ISSN: 2354 - 1431

http://tckh.daihoctantrao.edu.vn/

\title{
Bức tranh ngôn ngữ về thế giới - đặc trưng văn hoá - tư duy cộng đồng ngôn ngữ
}

Đỗ Việt Hùng ${ }^{a}$

a Truòng Đại học Sur phạm Hà Nội

\section{Article info}

Recieved:

02/6/2017

Accepted:

03/8/2017

\section{Keywords:}

Linguistic worldview

Culture-thinking;

World's division;

Vocabulary.

\begin{abstract}
The linguistic worldview is formed in the daily perception of a language community. It is the overall image of the world which is reflected in language, it is the mode of accessing and the worldwide structure, it is the practical conceptualization. In the relations with cultural characteristics - community thinking, it can be considered from many sides, especially the world's division of a community through vocabulary of language. Statistics, comparisons, comparisons of identifying words have reflected the world's division of a community. Dividing the world into meaning pieces of words has created the diversity of thinking and community culture. On the one hand, it has had a great influence on the formation of language; on the other hand it has brought the richness of thinking and culture which also makes the distinctions in the lexical meaning of words.
\end{abstract}

\section{1. Đặt vấn đề}

Khái niệm "bức tranh ngôn ngữ về thế giới” bắt nguồn một mặt từ tư tưởng của V.Humboldt và các nhà Tân Humboldt, mặt khác từ các tư tưởng của các nhà Ngôn ngữ học dân tộc Mĩ mà phần nào là từ giả thuyết tương đối về ngôn ngữ của Sapir - Whorf. Khái niệm này ngày càng được nhiều nhà khoa học trong và ngoài nước quan tâm, nhất là khi Ngôn ngữ học tri nhận phát triển.

Ngôn ngữ học trong nước phải kể đến các nhà khoa học như Lý Toàn Thắng, Trần Văn Cơ, Nguyễn Đức Tồn, Lê Quang Thiêm... Theo quan niệm phổ biến của các nhà Ngôn ngữ học tri nhận trong và ngoài nước, có thể nhận định: Bức tranh ngôn ngũ về thế giới được hình thành trong nhận thức hằng ngày của một cộng đồng ngôn ngũ là tổng thể hình ảnh về thế giới được phản ánh trong ngôn ngũu, là phuoong thức tiếp nhận và cấu trúc hoá thế giới, là sụ ý niệm hoá thực tế.

\section{Nội dung vấn đề}

Phần lớn các nhà Ngôn ngữ học tri nhận đều nhận định rằng bức tranh ngôn ngữ về thế giới gắn với nhận thức về thế giới của cộng đồng ngôn ngữ được hình thành trong lịch sử và được truyền từ thế hệ này sang thế hệ khác. Popora Z.D. và Sternin I.A. định nghĩa: "Bức tranh ngôn ngữ về thế giới là hình ảnh về thực tế được thể hiện trong các tín hiệu ngôn ngữ và nghĩa của chúng - sự phân cắt thế giới bằng ngôn ngữ, sự sắp đặt các sự vật, hiện tượng bằng ngôn ngữ và là thông tin về thế giới ẩn chứa trong hệ thống nghĩa của từ’. [81, trang 68]

Mặc dù có những điểm chung nhưng mỗi ngôn ngũ tự nhiên có bức tranh ngôn ngữ về thế giới của riêng mình. Dẫn quan điểm của Iu.D. Aprexjan, Nguyễn Đức Tồn khẳng định: "Từ quan điểm của Ngôn ngữ học tri nhận, phương thức ý niệm hoá, hay còn gọi là cách nhìn thế giới, một phần có tính phổ quát, một phần có tính đặc thù dân tộc, nên những người nói những thứ tiếng khác nhau có thể nhìn thấy thế giới hơi khác nhau thông qua lăng kính ngôn ngữ của mình". [59, trang 93]

Với quan niệm về bức tranh ngôn ngữ về thế giới như cách nhìn riêng đặc thù cho cộng đồng ngôn ngữ, chúng ta hoàn toàn có thể tiếp cận các vấn đề ngôn ngữ trong mối quan hệ với đặc trưng văn hoá - tư duy cộng đồng. Một trong những bình diện quan trọng để tìm hiểu đặc trưng văn hoá - tư duy cộng đồng từ ngôn ngữ là bình diện từ vựng. Cụ thể, xem xét cách nhìn của cộng đồng từ các góc độ:

(i) Sự chia cắt thế giới của cộng đồng thể hiện qua vốn từ của ngôn ngữ;

(ii) Quan niệm của cộng đồng về sự vật, hiện tượng thông qua các phương thức định danh của ngôn ngữ;

(iii) Quan niệm của cộng đồng về sự vật, hiện tượng thông qua ý nghĩa của từ;

(iv) Quan niệm của cộng đồng thông qua hiện tượng chuyển nghĩa từ vựng;

(v) Quan niệm của cộng đồng thông qua các ngữ cố định (thành ngữ); 
(vi) Quan niệm của cộng đồng thông qua hiện tượng biểu trưng hoá của từ ngữ.v.v.

Trong bài viết này chúng tôi bàn đến góc độ thứ nhất: Sự chia cắt thế giới của cộng đồng thể hiện qua vốn từ của ngôn ngữ

Ý nghĩa của tù, trong đó có ý nghĩa biểu vật, bắt nguồn tù các sụ vật, hiện tượng trong thế giới mà không phải là chính các sụ vật, hiện tuợng - Đó là nhận định khá phổ biến và gần như được hầu hết các nhà từ vựng học, ngữ nghĩa học chấp nhận. Một bằng chứng quan trọng cho nhận định này là nếu ý nghĩa biểu vật của từ trùng với các sự vật, hiện tượng của thế giới thì số lượng từ ngữ trong các ngôn ngữ khác nhau phải như nhau. Nhưng trên thực tế, không phải như vậy. Số lượng các từ ngữ trong mỗi ngôn ngữ là riêng, không bằng nhau giữa các ngôn ngữ. Số lượng từ ngữ của ngôn ngữ phản ánh sự chia cắt thế giới của cộng đồng ngôn ngữ. Việc so sánh số lượng từ ngữ giữa các ngôn ngữ dẫn đến hai kết quả quan trọng. Thứ nhất, có thể thấy những sự vật, hiện tượng chỉ có ở cộng đồng này mà không có ở cộng đồng khác, chẳng hạn như nem (tên gọi một món ăn) chỉ có trong tiếng Việt. Thứ hai, điều này quan trọng hơn, là chỉ ra được cách nhìn, cách cảm nhận thế giới của mỗi cộng đồng ngôn ngữ, đặc biệt là tính khái quát và cụ thể trong nhận thức dân tộc về thế giới. Chẳng hạn, silk (loại vải tơ tằm) trong tiếng Anh có thể ứng với nhiều thứ khác nhau trong tiếng Việt: tơ, lụa, lượt, là, gấm, vóc, nhiễu, the, đoạn, lĩnh, đũi, nái, sồi, thao, vân, địa... [2, trang 404] cho thấy mức khái quát cao của từ silk trong nhận thức của người Anh về "các loại vải tơ tằm", còn người Việt có nhận thức về những loại vải này cụ thể hơn nhiều. Tương tự, từ xanh của tiếng Việt ứng với blue, green trong tiếng Anh và 3 từ trong tiếng $\mathrm{Nga}$ синий, зелённый, голубой. Cũng như vậy, tiếng Việt có nhiều từ như tắm, giạt, rủa (người Việt phân biệt rất rõ các đối tượng được "làm sạch" để sử dụng tắm, giặt hay rưa) tương ứng với động từ to wash trong tiếng Anh. Hoặc người Nga phân biệt rõ tắm trong bể bơi (sông, hồ...) - куnатьcя với tắm trong buồng tắm (принимать дyu) nhưng người Việt chỉ có một từ tắm chỉ chung cho "làm sạch thân thể" (không có nét nghĩa ở đâu). So sánh lượng từ ngữ của các ngôn ngữ, như vậy, sẽ có được những hiểu biết về sự chia cắt thế giới của cộng đồng ngôn ngữ, từ đó nhận ra những dấu hiệu đặc trưng văn hóa - tư duy của tộc người. Điều này khá quan trọng đối với thực tiễn nghiên cứu ngôn ngữ văn hóa ở một đất nước đa dân tộc như nước ta. Chẳng hạn người Việt chỉ có một từ duy nhất để chỉ thế giới tinh thần, đó là linh hồn. Nhưng với người Thái thì khác, bắt nguồn từ quan niệm "mỗi người có 80 hồn vía, 30 hồn ở phía trước, 50 hồn ở phía sau”, tiếng Thái có tới hơn 80 từ để chỉ linh hồn, như khuân hua (hồn đầu); khuân ék (hồn óc), khuân kmom (hồn chóp), khuân phôm (hồn tóc); khuân puống nốm (hồn bầu vú); khuân hua chau (hồn quả tim); khuân tọng nọi (hồn bụng nhỏ); khuân mốc luông (hồn bụng to)...

Một trong những phương pháp quan trọng trong nghiên cứu mức độ "chia cắt" thế giới là lí thuyết xác lập ô trống. Phương pháp này dựa trên sự đối chiếu - so sánh các ngôn ngữ ở nhiều bình diện khác nhau, trong đó có so sánh vốn từ vựng giữa các ngôn ngữ theo mô hình ma trận để xác lập các ô trống ở mỗi ngôn ngữ (ô trống là ô không có từ ngữ tương ứng về nghĩa với từ ngữ trong ngôn ngữ được đối chiếu - so sánh). Nguyễn Đức Tồn và các học trò đã sử dụng phương pháp này để tiến hành đối chiếu các từ ngữ chỉ bộ phận cơ thể người, tên gọi động vật và tên gọi thực vật. Kết quả của các nghiên cứu này như sau:

- Số lượng bộ phận cơ thể người được "chia cắt" định danh trong tiếng Việt là 289 và trong tiếng Nga là 227. Để định danh những bộ phận cơ thể người, tiếng Việt sử dụng 397 tên gọi, tiếng Nga sử dụng 251 (Dẫn theo [3], trang 227).

- Về tên gọi động vật, theo thống kê của Nguyễn Thuý Khanh, tiếng Việt có 623 tên gọi, còn tiếng Nga có 394 tên gọi (Dẫn theo [3], trang 229).

- Về tên gọi thực vật, theo thống kê của Cao Thị Thu, tiếng Việt có 657 tên gọi. (Dẫn theo [3], trang 230).

Những số liệu đồng đại về số lượng từ ngữ ở các ngôn ngữ cho phép có được những nhận xét chính xác và thú vị về đặc điểm nhận thức thế giới, mức độ "chia cắt" thế giới của mỗi cộng đồng ngôn ngữ. Tuy nhiên, nếu chỉ dừng ở số liệu đồng đại, thì kết quả có thể chưa thật chính xác về đặc điểm nhận thức thế giới ở góc độ phân chia thế giới, nếu coi "bức tranh ngôn ngữ về thế giới” là một khái niệm hình thành trong lịch sử cộng đồng. Để chính xác hoá những nhận định về sự "chia cắt" thế giới cần kết hợp với nghiên cứu nguồn gốc các từ ngữ của cộng đồng. Phân tích nguồn gốc các tên gọi, đặc biệt chú ý đến số lượng các từ ngữ thuần Việt, so sánh với các tên gọi của tiếng Nga, Nguyễn Đức Tồn nhận định: "Những cứ liệu đã dẫn chỉ ra rằng số lượng tên gọi thuần Việt của bộ phận cơ thể người ít hơn so với các tên gọi thuần Nga. Để định danh bộ phận cơ thể, người Nga thường dùng từ ngữ trong vốn từ "của mình" hơn. Điều này cho phép giả định có lẽ xa xưa sự phạm trù hoá hiện thực khách quan ở phạm vi bộ phận cơ thể người Nga là chi tiết hơn so với người Việt. Trong "bức tranh ngôn ngữ về thế giới” ở người Việt khi đó có nhiều ô trống, hay "vết trắng" hơn so 
với người Nga. Song người Việt đã nhanh chóng lấp đầy những khoảng trống ấy bằng cách vay mượn chủ yếu từ tiếng Hán..." [3, trang 228] và "nếu đối chiếu sự định danh thế giới động thực vật của người Việt và người Nga theo tham tố này (nguồn gốc tên gọi) có thể thấy rằng bức tranh ngôn ngữ về động vật của tiếng Nga có nhiều ô trống hơn so với bức tranh tương ứng trong tiếng Việt bởi vì tên gọi thuần Việt của động vật chiếm tới 93\%, của thực vật tới 76,9\% (505/657), trong khi đó tên gọi động vật thuần Nga chỉ chiếm 78\% (155/198)" [3, trang 232, 233].

Thống kê, đối chiếu, so sánh số lượng từ không chỉ áp dụng đối với việc nghiên cứu các ngôn ngữ của quốc gia, dân tộc mà còn có thể sử dụng để tìm ra những đặc điểm riêng của các nhóm phương ngữ trong cộng đồng dân tộc chung. Khảo sát các từ ngữ chỉ "cá" trong phương ngữ Nghệ Tĩnh, Hoàng Trọng Canh đã thu thập được hơn 200 từ - gấp hai lần số lượng từ chỉ "cá" trong Tù điển tiếng Việt. Phân tích sự khác biệt về số lượng đó, Hoàng Trọng Canh đã nhận xét: "Sự phong phú về số lượng của lớp từ ngữ chỉ "cá" trong phương ngữ Nghệ Tĩnh không chỉ phản ánh sự phong phú về hiện thực nghề cá, nhiều loại cá được phản ánh gọi tên mà còn cho thấy đặc điểm phân cách đối tượng một cách cụ thể theo những đặc trưng lựa chọn mang tính biệt loại rõ ràng của cách cảm nhận, tri giác của người Nghệ. Chẳng hạn, người Nghệ không dừng lại ở tên gọi mưc có ý nghĩa "chung chung" mà trong ý niệm, họ phân $m u ̛ c$ ra thành nhiều loại, nên mới có nhiều tên gọi khác nhau: mưc lá, mưc cơm, mưc ống, mưc nang, mưc tuộc..."[1].

\section{Kết luận}

Dễ dàng nhận thấy, đối chiếu đồng đại và lịch đại theo phương thức ma trận về tính [ \pm tương ứng] từ ngữ giữa các ngôn ngữ khác nhau là hướng nghiên cứu có triển vọng lớn trong xác định mức độ "chia cắt" thế giới của cộng đồng ngôn ngữ thành tên gọi và qua đó xác định cách nhìn hay "bức tranh ngôn ngữ về thế giới" của mỗi dân tộc. Và, việc đối chiếu này còn có thể ứng dụng trong nội bộ một ngôn ngữ đối với các phương ngữ và thổ ngữ của ngôn ngữ đó để nhận thấy "bức tranh ngôn ngữ về thế giới" của từng địa phương trong một quốc gia, một dân tộc.

"Chia cắt" thế giới thành các "mẩu" nghĩa của từ làm nên sự đa dạng của tư duy và văn hoá cộng đồng, một mặt, có ảnh hưởng lớn đến sự hình thành số lượng từ của ngôn ngữ, mặt khác sự phong phú của tư duy và văn hoá còn làm nên những khu biệt tinh tế trong nghĩa từ vựng của các từ. So sánh các từ chỉ màu "xanh" (lá cây) giữa tiếng Việt với các ngôn ngữ khác như tiếng Nga зелённыцй và tiếng Anh - green, dễ thấy tiếng Việt có nhiều từ hơn - xanh, xanh xanh, xanh um, xanh rì... và sự khu biệt nghĩa giữa các từ này tinh tế hơn so với nhiều ngôn ngữ khác. Điều này làm cho việc dịch nghĩa của các từ này sang các ngôn ngữ tương ứng sẽ khó khăn hơn.

Những khác biệt về "bức tranh ngôn ngữ về thế giới" là những kết quả nghiên cứu không chỉ nhằm vào việc khám phá các đặc trưng văn hoá, tư duy của mỗi cộng đồng, sự khác biệt giữa các cộng đồng về nhận thức thế giới mà còn có ý nghĩa quan trọng trong giảng dạy ngôn ngữ cả cho người bản ngữ và người nước ngoài.

\section{TÀI LIỆU THAM KHẢO}

1. Hoàng Trọng Canh (2011), Một kiểu định danh và biểu trung đối với tên gọi nghề "cá” trong phưong ngũ Nghệ Tinh, Website của Trường Đại học Vinh;

2. Trần Ngọc Thêm (1998), Tim về bản sắc văn hóa Việt Nam., Nxb TP. Hồ Chí Minh.;

3. Nguyễn Đức Tồn (2010), Đặc trung văn hóa - dân tộc của ngôn ngũ và tu duy, Nxb Từ điển Bách khoa. 